\title{
Adhesive Certified According to European Marine Equipment Directive
}

Follmann has gained certification according to the European Marine Equipment Directive (MED) for its dispersion adhesive for the wood and furniture industry, which has proven its worth over many years.

$\mathrm{M}$ odern dispersion adhesives are increasingly expected to exceed the standard requirements for a permanent, secure, water-proof and/or heat-proof bond. Nowadays, in addition to health issues such as the use of safe raw materials, safety aspects are growing in relevance in the wood and furniture industries.

Follmann therefore put its dispersion adhesive Folco LIT D3 W91 to the safety test with regard to flame retardance. The product satisfies the stringent requi-

rements in terms of flame retardant properties, smoke density and toxicity according to the European Marine Equipment Directive (MED), and can now carry the Wheelmark symbol that is an essential requirement in the ship interior finishing sector. As a result, Follmann can now offer its customers an EC-type examination certificate which confirms compliance with the flame retardance, smoke density and toxicity requirements as per IMO FTP Code Parts 2 and 5.

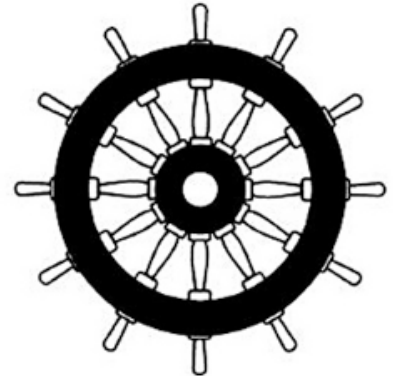

The Wheelmark symbol certifies that the product satisfies the stringent requirements in terms of flame retardant properties, smoke density and toxicity according to the European Marine Equipment Directive (MED)

\section{EURADH 2012 Concludes with a Positive Result}

The 9th European Adhesion Conference - EURADH, which is organised by DECHEMA, was held from 16 to 20 September 2012 at the Graf-Zeppelin-Haus venue in Friedrichshafen. The topics discussed ranged from Fundamental Adhesion issues to Industrial Challenges, with one of the two parallel sessions being dedicated to Mechanics of Adhesive Joints and the other to Ageing and Fatigue.

A 11 papers presented were on a high scientific level and initiated intensive discussions. The approximately 60 posters always drew crowds during the poster sessions, making it extremely difficult for the jury to decide on the winners of the three prizes offered. In the end, they went to Y. Kawano from Yokohama National University (Application of epoxy resins of steam explosion lignin derived from softwood), L. Krogh from Saarland University (Determination of viscoelastic properties in adhesive joints) and M. Alfano, King Abdullah University of Science and Technology, Thuwal/SAR (Identification of a cohesive zone model for debonding of adhesive joints).

EURADH was well-attended, with 175 participants from 17 countries, with Japan making up the third-largest delegation after Germany and France. This is certainly also due to the fact that the next WCARP world conference, which has close ties with EURADH, will take place in Nara, Japan, from 7 to 10 September 2014 (further information: www. adhesion.or.jp/wcarp). The next EURADH has also already been planned and will be held from 22 to 25 April 2014 in Alicante, Spain.

This year's event concluded with an extremely positive result overall. There was a very intensive exchange of ideas and experiences among the participants from industry and institutes and from the different countries and specialist fields, the congress centre and its surroundings provided an excellent atmosphere, and sunshine and excellent catering also helped to make the 9th EURADH conference a success.

There has been a lot of activity recently among the group of EURADH countries. In the past, the conference was held alternately in France, the UK and Germany. Spain joined the list as the fourth country in 2010 with its own Adhesion Society, while the Portuguese Adhesion Society was added as the fifth member organisation during EURADH 2012. As both Iberian countries have close links with South America, this promises to open up an even wider group of participants for future events.

\section{Dr. Andreas Hartwig}

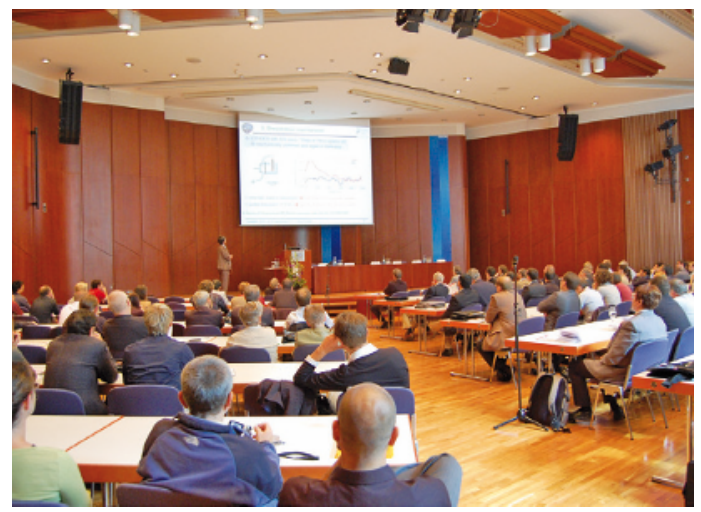

All papers presented were on a high scientific level and were always well-attended. 